\title{
LAS OBRAS ARQUITECTÓNICAS DE LA BENEFICENCIA EN MAR DEL PLATA (ARGENTINA) COMO DISPOSITIVOS DISCIPLINARES (1900-1930). ANÁLISIS A TRAVÉS DE LA PERSPECTIVA DE FOUCAULT
}

DOI: https://doi.org/10.18861/ania.2019.9.2903

Arq. Romina Fiorentino M.Sc.

https://orcid.org/0000-0002-6399-8758 


\section{ARQ. ROMINA FIORENTINO M.SC.}

Arquitecta, docente e investigadora del Instituto de Estudios de Historia, Patrimonio y Cultura Material, Facultad de Arquitectura, Urbanismo y Diseño de la Universidad Nacional de Mar del Plata (Argentina). Actualmente estudiante de las carreras de Postgrado del Doctorado de Trabajo Social Doctorado en Trabajo Social, Universidad Nacional de Rosario - Extensión Áulica Universidad Nacional de Mar del Plata (Argentina) y la Maestría en Gestión e Intervención del Patrimonio Arquitectónico y Urbano, Facultad de Arquitectura, Urbanismo y Diseño de la Universidad Nacional de Mar del Plata (Argentina).

FECHA DE RECEPCIÓN: 22 de enero de 2019.

FECHA DE ACEPTACIÓN: 7 de mayo de 2019.

REGISTRO BIBLIOGRÁFICO: FIORENTINO, R. (2019). Las obras arquitectónicas de la beneficencia en Mar del Plata (Argentina) como dispositivos disciplinares (1900-1930). Anales de Investigación en Arquitectura, 9 (1), 83-103. 


\section{RESUMEN}

Este trabajo se enmarca dentro avances de Investigaciones desarrolladas en el "Grupo Patrimonio" de la FAUD-UNMDP, respecto a la Preservación del Patrimonio Arquitectónico del Asistencialismo y del Doctorado de Trabajo Social. Se toman como caso de estudio dos obras arquitectónicas construidos por la Sociedad de Beneficencia en la Argentina, emplazadas en la ciudad de Mar del Plata, tales como el "Solarium" (hoy demolido) y el actual "Instituto Saturnino Unzué" (antiguo asilo de la ciudad, declarado Monumento Nacional) que se construyeron en las primeras décadas del siglo XX. Estos edificios se analizan desde la perspectiva foucaultiana de poder, como "dispositivos disciplinares" implantados dentro de la ciudad, respecto al proceso histórico de construcción del Estado moderno.

Por otro lado, es de destacar que estas obras, más allá de sus valores arquitectónicos, poseen un gran "valor testimonial" como documentos históricos en sí mismas, ya que son enclaves espaciales en el que confluyen el pasaje de los diferentes paradigmas de la asistencia social a lo largo de su historia. Para este estudio se tomaron diferentes fuentes documentales y bibliográficas, entre ellas álbumes de la misma Sociedad de Beneficencia, planimetrías y fotos históricas, que permiten ver estas problemáticas plasmadas en la historia de sus muros, sus documentos y reglamentaciones.

Palabras Clave: Beneficencia - dispositivos disciplinares - arquitectura del asistencialismo - Foucault. ABSTRACT

This work is part of the research carried out in the Heritage Group of the FAUD-UNMDP, with respect to the Preservation of the Architectural Heritage of Welfare and the Doctorate of Social Work. Two architectural works constructed by the Society of Charity in Argentina, located in the city of Mar del Plata, such as the "Solarium" (today demolished) and the current "Saturnino Unzué Institute" (formerly the the city, declared a National Monument) that were built at the beginning of the 20th century. These buildings are analyzed from the Foucaultian perspective of power, as "disciplinary devices" implanted within the city, with respect to the historical process of construction of the modern State.

On the other hand, it is noteworthy that these works, beyond their architectural values, have a great "testimonial value" as historical documents in themselves, since they are spatial enclaves in which the passage of the different paradigms of assistance converge social throughout its history. For this study different documentary and bibliographical sources were taken, among them albums of the same Society of Beneficence, planimetry and historical photos, that allow to see these problems expressed in the history of its walls, its documents and regulations.

Keywords: Beneficence, disciplinary devices, architecture of assistance. 


\section{INTRODUCCIÓN}

Como se menciona este trabajo se enmarca, por un lado, dentro de las investigaciones desarrolladas en el "Grupo Patrimonio" del IEHPAC-FAUD-UNMDP al cual pertenezco, respecto a la Preservación del Patrimonio Arquitectónico del Asistencialismo, y por otro lado, a los avances de tesis del Doctorado de Trabajo Social, el cual curso actualmente y en el que profundizo la perspectiva de Michel Foucault en el análisis de los edificios de la Sociedad de Beneficencia. Es de destacar, que además, estos edificios dan cuenta y poseen un gran "valor testimonial" como documento histórico en sí mismos, ya que encarnan la historia de la asistencia social (desde sus primeras formas), hasta la inserción de "trabajadores sociales" en el Instituto, como parte de la instauración de la carrera de Trabajo Social como campo científico y carrera de grado.

En relación al estado de la cuestión se encuentran trabajos publicados del mencionado "Grupo Patrimonio" (Fiorentino, 2013; Paris Benito, 2013), que desde un corte netamente histórico y de resguardo patrimonial se aborda las obras de la Beneficencia en Mar del Plata, cuyo enfoque de análisis no contempla relaciones espaciales de poder como dispositivos, ni introduce aspectos de la teoría de Foucault. A nivel internacional, y desde la exploración de estudios que aborden la dimensión espacial y de poder, encontramos el análisis arquitectónico y lingüístico que realizan
Deborah Cameron y Thomas Markus (2002), en cuyo libro The words between the spaces, ponen en relación la arquitectura, el poder y la palabra, haciendo mención a algunos ejemplos de instituciones -como el "asilo para locos" de Glasgow-y las referencias al poder disciplinario, aunque su impronta foucaultiana no sea explícita y posean pocas citas de este autor en su texto, como señala Rodrigo Amuchástegui (2008). Este último y desde su tesis doctoral -de carácter teórico dentro de Filosofía y Letras de la UBA ${ }^{1}$ - rastrea y analiza los textos de la obra de Foucault en sus conceptualizaciones pictórico-visuales y espaciales, explorando esta dimensión particular de la obra. Por otro lado, Raphaël Fischler (1995), en una orientación similar al texto de Cameron y Markus, propone una variante temática de la práctica profesional arquitectónica, poniendo al descubierto las relaciones de poder que allí se entrecruzan, como un elemento necesario a las prácticas proyectivas (Amuchástegui, 2008). Otro antecedente relacionado se encuentra en el trabajo de Cecilia Raffa, enfocado en el estudio del modelo panóptico en otra tipología funcional relacionada con la arquitectura penitenciaria argentina, específicamente a la primera cárcel en la ciudad de Mendoza construida en1864.

Por ello y en virtud de la falta de investigaciones que aborden las obras arquitectónicas de la Sociedad de Beneficencia como dispositivos disciplinares de poder, este trabajo propone

1 Universidad Nacional de Buenos Aires. 
las obras "Solarium" (hoy demolido) y el actual "Instituto Saturnino Unzué" de Mar del Plata como casos de estudio. El tipo de investigación es de tipo aplicada, siendo su metodología de tipo cualitativa. La perspectiva foucaultiana evidenciada en este estudio nos ubica en un enfoque de tipo interpretativo, frente al análisis de diversos discursos tales como reglamentos, prácticas y configuraciones espaciales, y edificios, a las que nos disponemos a interrogar, desde una investigación que se orienta a una labor histórico-crítica (de tipo arqueológica y genealógica²) que caracteriza la propuesta de Foucault, en donde los viejos testimonios se comportan como síntomas del presente.

\section{MAR DEL PLATA Y LA SOCIEDAD DE BENEFICENCIA: "ORGANIZACIONES DISCIPLINARES DE LA CIUDAD”}

Diferentes Sociedades de Beneficencia, entre ellas la Sociedad de Beneficencia de la Capital Federal, actuaron en la ciudad de Mar del Plata convocando a diversos profesionales para

2 Dentro de las corrientes de reconstrucción histórica, la genealogía es una vertiente que sienta sus bases en Nietzsche y que luego es tomada por Foucault y otros autores. En este sentido Martínez-Novillo (2010) declara que se puede entender "la genealogía como un proyecto de análisis iniciado por Nietzsche y reapropiado (y reelaborado) de una forma singular por Foucault". Michel Foucault (1988 [1971]) enuncia que "La genealogía exige, por tanto, el saber minucioso, gran cantidad de materiales apilados, paciencia. Sus "monumentos ciclópeos" no debe derribarlos a golpe de "grandes errores benéficos", sino de "pequeñas verdades sin apariencia, establecidas por un método severo"." diseñar y llevar a cabo edificios destinados a la asistencia social. Estas sociedades, en conjunción con instituciones públicas y privadas, son promovidas por organismos gubernamentales como aquellas que asumen el rol de políticas de salud y las medidas necesarias para brindar amparo social en situaciones límites de enfermedad, muerte o abandono de la minoridad. En ellas intervinieron profesionales de diferentes disciplinas (médicos, ingenieros y arquitectos, entre otros), que se capacitaron en las áreas de salud junto al desarrollo de las corrientes higienistas de la época.

Desde la perspectiva de Foucault (1993) durante largo tiempo estos grupos religiosos y asociaciones de beneficencia desempeñaron un rol central en la "organización de disciplina” de la población. En este sentido se multiplicaron las iniciativas de estos grupos, que poseían objetivos de diferente carácter, entre ellos religiosos (la conversión y la moralización), económicos (el socorro y la incitación al trabajo), o políticos (lucha contra el descontento o la agitación). Éstos se enuncian explícitamente en sus reglamentos, actas y documentos, como el caso de las compañías de caridad de las parroquias parisienses, en donde se precisan “(...) estabilidad del alojamiento, conocimiento de las oraciones, frecuentación de los sacramentos, conocimiento de un oficio, moralidad (y 'si no han caído en la pobreza por su culpa'); en fin, es preciso informarse hábilmente de qué manera se comportan en 
su hogar, si se hallan en paz entre sí y con sus vecinos, si se cuidan de educar a sus hijos en el temor de Dios" (Foucault, 1993 p. 216).

En relación a lo expresado en el Acta de instalación del Decreto de creación de la Sociedad de Beneficencia de la Capital de 1823 se enuncian tres objetos primordiales que han dirigido al gobierno en la erección de la Sociedad de Beneficencia: “La perfección de la moral, el cultivo del espíritu en el bello sexo y la dedicación del mismo a lo que se llama industria y que se resulta de la combinación y ejercicio de aquellas cualidades".

En su obra "Vigilar y Castigar", Foucault hace referencia a un reglamento de fines del siglo XVIII (perteneciente a Archivos militares de Vincennes) y a las medidas a adoptar cuando se declara la peste en una ciudad. Describe pasajes del mismo y pone atención en la inspección y constante vigilancia: “La inspección funciona sin cesar. La mirada está por doquier en movimiento (...) vigilan sus actos (...) Esta vigilancia se apoya en un sistema de registro permanente: informes de los síndicos a los intendentes, de los intendentes a los regidores o al alcalde. Al comienzo del "encierro'” (1993 p. 201).

Esta vigilancia, inspección y registro permanente se hace presente en el reglamento de 1939 del ex Asilo Saturnino Unzué (el cual se basa en el Reglamento del Asilo de Huérfanos 1870, p. 410-413), unas de las obras de la Sociedad de Beneficencia en la ciudad de Mar del Plata. Extraemos algunos artículos del Reglamento que enuncian esta dinámica de vigilancia y control. Entre ellos encontramos:

Art. $5^{\circ}$ - Son sus atribuciones y deberes:

1) Ejercer superintendencia sobre el personal y control sobre las funciones que todos y cada uno de los empleados desempe $\neg$ ñan, velando por el fiel cumplimiento de las disposiciones Art. $10^{\circ}$ - Sus funciones (...) son: vigilar la administración de los servicios internos de orden doméstico y la higiene del establecimiento, la moralidad y cultura de sus moradores y (...), debiendo aten $\neg$ der en todos los casos las órdenes de la Comisión Inspectora.-

Art. $18^{\circ}$ - Los talleres estarán a cargo de sus respectivas Hermanas Directoras, cuyos deberes y atribuciones son:

1) Llevar un libro donde apuntarán minuciosamente las Órdenes que recibieren, el nombre, apellido y dirección del clien־te, (...)

2) Responsabilizarse del orden y disciplina de sus respectivos talleres (...)

3) Presentar a la Hermana Superiora cualquier queja que tuvieran de las niñas, ya sea de mala conducta, indolencia o falta de disposición para el trabajo a que se les hubiese de-dicado.-

Este tipo de instituciones conforman un dispositivo disciplinario, el cual se caracteriza por ser un espacio cerrado y vigilado en todos 
sus puntos, donde los individuos están insertos en un lugar fijo y sus movimientos se hallan controlados y registrados. Así, y como enuncia Foucault, todo esto conforma un modelo compacto del dispositivo disciplinario “(...) en el que un trabajo ininterrumpido de escritura une el centro y la periferia, en el que el poder se ejerce por entero, de acuerdo con una figura jerárquica continua, en el que cada individuo está constantemente localizado, examinado y distribuido entre los vivos, los enfermos y los muertos" (1993 p.202).

Estos dispositivos ya no eran instalados en espacios marginales de la ciudad, sino establecidos estratégicamente acompañando el auge económico de ciertas áreas. De este modo, se implantan en sectores centrales y más productivos de la sociedad conectados con la producción manufacturera y la trasmisión de conocimientos a lo largo del siglo XVIII, tendencia que multiplica, por un lado, el número de las instituciones de disciplina, y por otro, la disciplina de los aparatos existentes (Foucault, 1993). En este sentido, vemos como paralelamente al surgimiento del nuevo pueblo de Mar del Plata hacia fines del siglo XIX y principios del XX (el que se convierte en la nueva Villa Balnearia Nacional de la elite porteña, se instalan las obras de la Sociedad de Beneficencia de la Capital y las Damas Vicentinas, tales como el Hospital Marítimo, el Asilo Unzué y el Solarium.

\section{EL SOLARIUM Y EL ASILO SATURNINO UNZUÉ: DISPOSITIVOS ARQUITECTÓNICOS DISCIPLINARES}

\author{
Tanto el Asilo Saturnino Unzué como el \\ Solarium, son algunos de los principales \\ edificios construidos por la Sociedad de \\ Beneficencia en la ciudad de Mar del Plata. \\ Estas obras conforman aquellas "instituciones \\ de disciplina" que se instalan en la ciudad, \\ por parte de los grupos dominantes de la elite \\ económica y política.
}

El Panóptico de Bentham, según Foucault, es la figura arquitectónica de estos espacios disciplinarios, que permiten la vigilancia jerárquica y el control permanente. Por lo tanto, "el panoptismo es el principio general de una nueva "anatomía política” cuyo objeto y finalidad no son las relaciones de soberanía, sino las relaciones de disciplina" (1993 p. 213). La arquitectura del Panóptico se concibe como un edificio circular, donde las celdas de los prisioneros se disponen concéntricamente en el perímetro en torno a una torre de vigilancia ubicada en el centro. La torre, a la que se accede sin puertas ni entradas de luz, cuenta con ventanas cubiertas por persianas con el fin de no delatar la presencia del carcelero.

El concepto de esta "simple idea de arquitectura" es permitir que un único observador pueda observar/vigilar (-opticon) a todos (Pan-) los prisioneros sin que los mismos sean capaces de determinar si están siendo observados o 


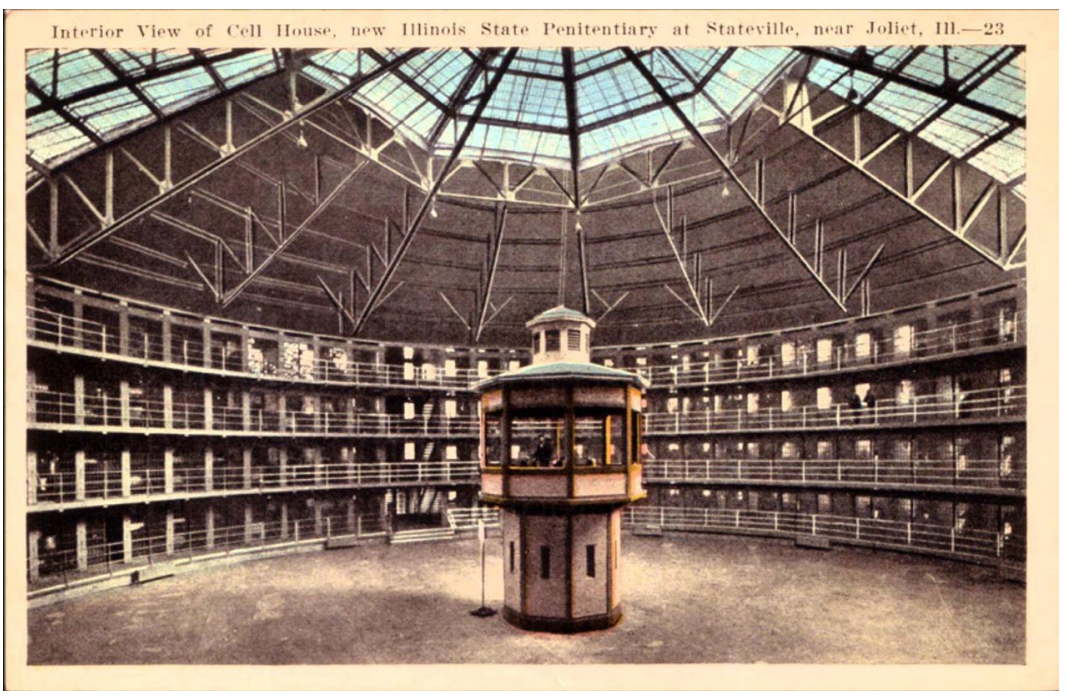

Figura 1.

Interior de la penitenciaría de Stateville, Estados Unidos, siglo XX. Se invierte el principio del calabozo; o más bien de sus tres funciones -encerrar, privar de luz y ocultar-; no se conserva más que la primera y se suprimen las otras dos. La plena luz y la mirada de un vigilante captan mejor que la sombra, que en último término protegía. La visibilidad es una trampa.
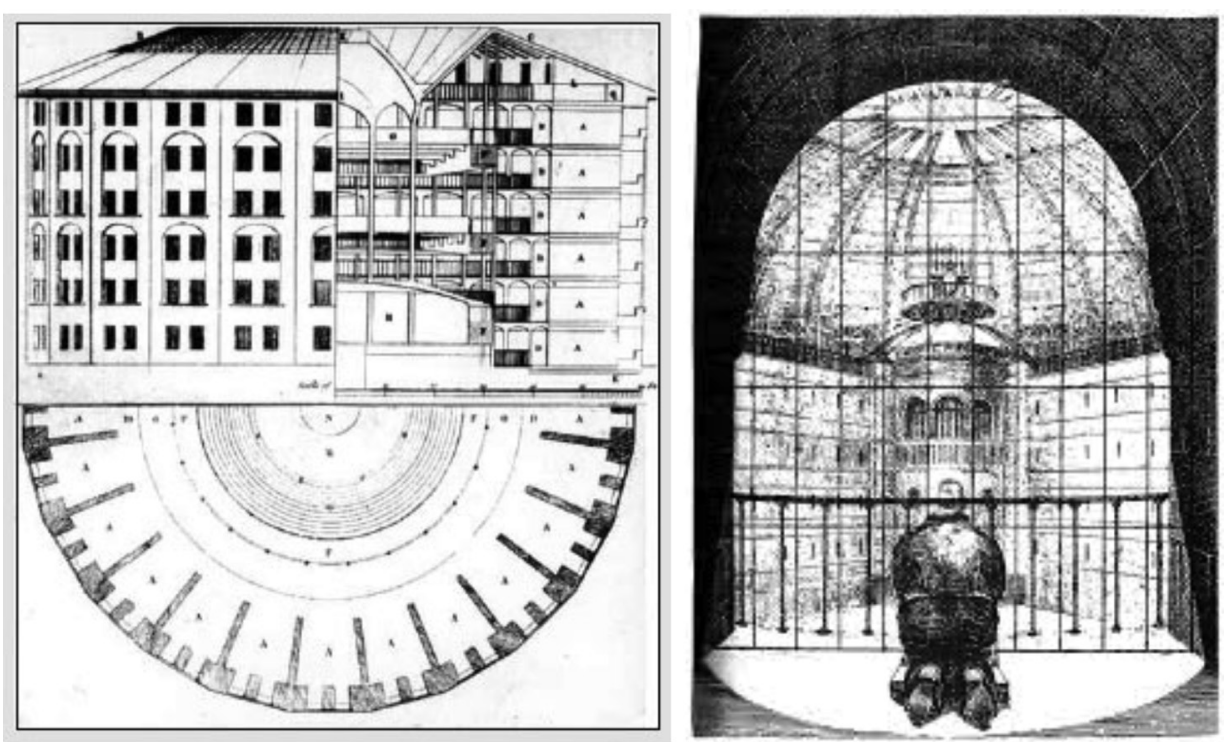

Figura 2.

(Izq.) Panóptico, corte y planta. Bentham: "una construcción en forma de anillo; en el centro, una torre, ésta, con anchas ventanas que se abren en la cara interior del anillo. La construcción periférica está dividida en celdas, cada una de las cuales atraviesa toda la anchura de la construcción. Tienen dos ventanas, una que da al interior, correspondiente a las ventanas de la torre, y la otra, que da al exterior, permite que la luz atraviese la celda de una parte a otra. Basta entonces situar un vigilante en la torre central y encerrar en cada celda a un loco, un enfermo, un condenado, un obrero o un escolar." (Der.) Proyecto de penitenciaría, 1840. Un recluso, en su celda, en oración ante la torre central de vigilancia. 
no, creando una atmósfera de omnisciencia invisible. Esta omnisciencia funciona como instrumento para reformar a los prisioneros, quienes al sentirse permanentemente vigilados se ven forzados a reprimir sus comportamientos "desviados". Para Foucault, la prisión desde sus inicios está "ligada a un proyecto de transformación de los individuos" (1978, p. 89), siendo un instrumento perfeccionado como la escuela o el cuartel que debe actuar con precisión científica. (Ver Fig. 1 y 2)

\section{EL SOLARIUM: EL DISPOSITIVO PANÓPTICO YEL PANOPTISMO}

Entre fines del siglo XIX y mediados del siglo $X X$, una de las enfermedades que provoca el mayor índice de mortalidad en la Argentina es la tuberculosis. Los primeros trabajos de Diego Armus abordan la tuberculosis en el territorio argentino como un problema social, y fundamentan el proyecto de ley para crear una Comisión Nacional de Lucha Antituberculosa en la Argentina. En este contexto, el doctor Emilio Coni, propone en 1892, la creación de un Hospital Marítimo en Mar del Plata para establecer una institución que atendiese a los niños afectados, ya que considera que al buen clima del lugar se suma la posibilidad de realizar baños de mar como un tratamiento eficaz para los niños convalecientes (Coni, 1895). Si bien la propuesta es desalentada por el Patronato de la Infancia, no sucede lo mismo con la Sociedad de Beneficencia de la Capital, que inmediatamente puso en marcha el proyecto. El $1^{\circ}$ de enero de 1893 , tras una visita de los doctores Juan Bosch y Antonio Arraga, directores de la Casa Expósitos y Hospital de Niños de Buenos Aires, elevan a la Sociedad de Beneficencia de la Capital Federal un informe en el que manifestan la conveniencia de fundar un Sanatorio Marítimo.

Así, la Sociedad de Beneficencia de la Capital en Mar del Plata funda un Sanatorio y Hospital y un Solarium Marítimo, cuya finalidad se extiende a la curación de la tuberculosis quirúrgica, y la vez, "vigorizar un buen número de niños expósitos (cuyas características fisiológicas son tan pobres) haciéndolos gozar, durante cierta época del año, de las influencias bienhechoras del lugar" (Jorge, 1932). Estas dos instituciones dedicadas al tratamiento de esa enfermedad (el Solarium y el Sanatorio y Hospital Marítimo), son financiadas y construidas por donaciones de las familias veraneantes en la ciudad (como la familia Unzué y Torquinst), y en el caso del Solarium, el dinero para su ejecución lo aporta el Presidente de la República Don Hipólito Yrigoyen.

Los trabajos son iniciados en 1915 y terminados en 1917. Se inaugura finalmente en febrero de 1918, siendo el primer edificio en el país dedicado específicamente al tratamiento de tuberculosis ósea de niños y luego de adultos: "La tuberculosis ósea que tantos estragos causa entre los niños, se combate eficazmente en un ambiente como este, en que pueden recibir la influencia de los rayos solares al borde del mar. 

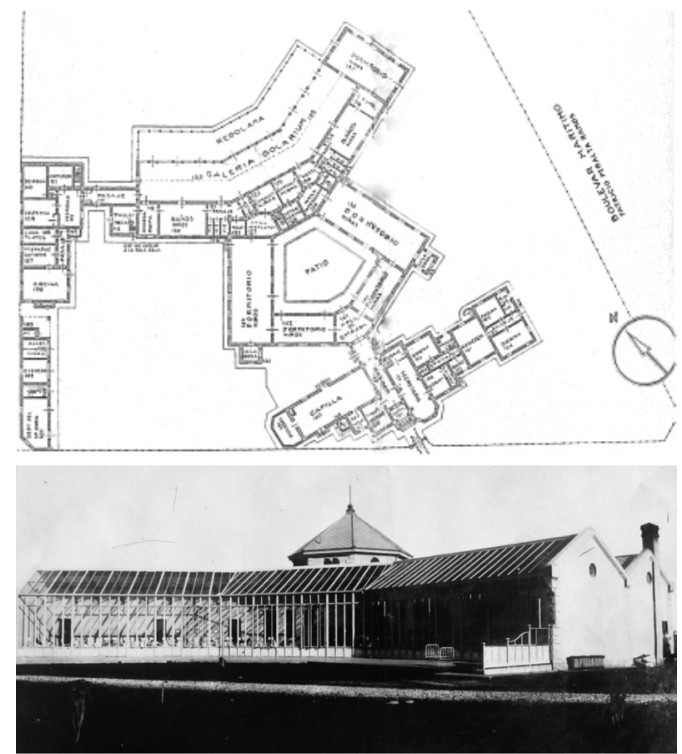

Figura 3

(Arriba) Plano general del conjunto edilicio del Solarum, ejecutado por la Oficina Técnica de las

Damas de Beneficencia. (Abajo) Galeria vidriada del Solarium. Fuente: Documento del archivo general de la Nación.

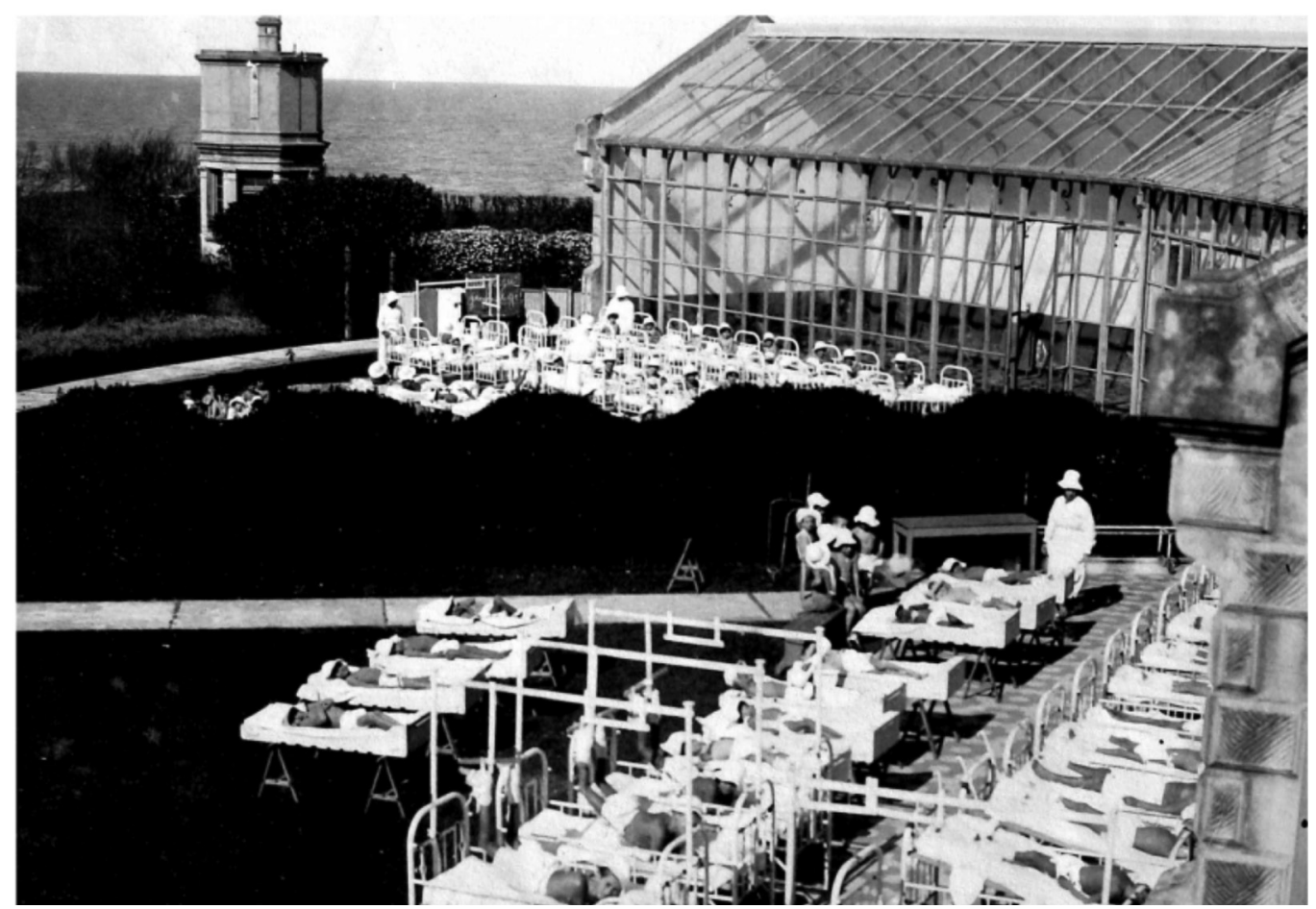

Figura 4.

Imagen del conjunto desde la galería y patio del Solarium. Fuente: Documento del archivo general de la Nación. 
Tenemos la esperanza de que en éste Solarium, que se ha construido e instalado de acuerdo a las últimas normas de la ciencia médica (...), encontrarán los pobres enfermitos la salud que tanto anhelan y el vigor que les permitirá ser elementos útiles a la sociedad." (Sociedad de Beneficencia de la Capital, Su origen y su desenvolvimiento, 1905).

Las imágenes del edificio, nos remiten al panóptico de Bentham, en la que podemos observar la torre central, ubicada sobre la figura del pentágono que conforma el esquema de la planta (Fig. 3 y 4). El cuerpo de los pabellones en forma de abanico que se abre hacia el norte, acristalado y transparente, permite vigilar y recorrer rápidamente con la mirada la galería y el posicionamiento de las camillas para los baños de sol de los niños. De esta manera, "el dispositivo panóptico dispone unas unidades espaciales que permiten ver sin cesar $y$ reconocer al punto (...) Basta entonces situar un vigilante en la torre central y encerrar en cada celda a un loco, un enfermo, un condenado, un obrero o un escolar" (Foucault, 1993, p.204).

Este sistema disciplinario espacial y moral, se extende a los diseños de diversas tipologías funcionales, más allá de las penitenciarías. En este sentido, el panóptico plantea una tecnología del poder que puede ser aplicable -como dice el propio Bentham- a otras instituciones como los hospitales, escuelas, cuarteles o fábricas, como el caso de este Sanatorio Marítimo. Cabe aclarar, que muchos de este tipo de instituciones mencionadas en el párrafo anterior, no son un panóptico en el sentido literal arquitectónico (o sea su estructura espacial no es "panóptica"), sin embargo, la manera como es gestionado por la administración pública cabe dentro de lo que Foucault denomina como "panoptismo"; en el cual las instituciones que supervisan el proyecto funcionan como "instituciones panópticas", en donde muchas veces la relación entre la arquitectura, sus habitantes y las autoridades (el poder) es panóptica. El Panóptico, como lo define Foucault, debe ser "entendido como un modelo generalizable de funcionamiento; una manera de definir relaciones de poder en términos de la vida diaria de los hombres" (Foucault, 1993 p. 205). Es también un laboratorio, que puede ser utilizado como máquina para experimentos, para alterar comportamientos, entrenar o corregir individuos.

\section{EL ASILO UNZUÉ, SISTEMA DISCIPLINAR DE COLOCACIÓN DEL SERVICIO DOMÉSTICO}

La multiplicación y "extensión de las instituciones disciplinarias no es, sin duda, otra cosa que el aspecto más visible de diversos procesos más profundos (...) la disciplina de taller, sin dejar de ser una manera de hacer respetar los reglamentos y las autoridades, de impedir los robos o la disipación, tiende a que aumenten las aptitudes, las velocidades, los rendimientos, y por ende las ganancias (...), y hace que entren los cuerpos en una maquinaria y las fuerzas en una economía."

(Foucault, 1993, p. 214) 
Como una de esas tantas instituciones disciplinarias se puede entender al "Ex-Asilo Saturnino Unzué"3 (1909), en cuyos fines se encuentra también la formación de servicio doméstico calificado de bajo costo, por lo tanto como un sistema institucional de colocación "que fabrican individuos útiles". En este sentido Foucault expresa que a comienzos de la Revolución, el objetivo que impregna a la enseñanza primaria es el de "fortificar", "desarrollar el cuerpo", disponer al niño para cualquier trabajo mecánico en el futuro, y así, las disciplinas funcionan cada vez más como técnicas que fabrican individuos útiles (1993).

En este sentido, Allemandi (2005) en su tesis de doctorado aborda la temática de la inserción laboral y de reclutamiento del servicio doméstico hacia fines del siglo XIX y principios del XX en Buenos Aires. De manera más amplia que otros autores, aborda aquellos circuitos de reclutamiento y colocación de sirvientes en ese entonces, en donde para conseguir un muchacho o muchacha "para servir" -además de publicar un aviso- está la posibilidad de dirigirse a establecimientos de beneficencia pública o a dependencias del Ministerio Pupilar

3 El Asilo Unzué fue una obra impulsada por las hermanas María de los Remedios Unzué de Alvear y Concepción Natalia Unzué de Casares -Damas de la Sociedad de Beneficencia- en 1906, y encargada al arquitecto Luis Faure Dujarric. El 7 de septiembre de 1911, las hermanas Unzué donan el Asilo a la Sociedad de Beneficencia de la Capital, quien en 1912 inaugura oficialmente la institución con la presencia del Dr. Roque Sáenz Peña, presidente de la Nación, bajo el nombre de "Hogar Saturnino E. Unzué”. de la ciudad, donde se entregan menores de edad a través un contrato donde se establecen “las condiciones de la colocación". De esta manera se aleja de los planteos que considera que los intermediarios surgieron solamente para armonizar dificultades, en un ámbito donde coexistieron diferentes lógicas económicas, políticas institucionales y prácticas sociales y culturales con diferentes racionalidades.

Menciona diversas instituciones intermediarias que se encargaron de la inserción laboral de mujeres "como sirvientas", como el caso del Colegio Asilo que albergaron jóvenes provenientes de otras provincias o países carentes de contactos al llegar a la ciudad de Buenos Aires. Este es dirigido por la "Asociación Protectora de la Joven Sirvienta" creado en 1912, que ofrece instrucción "intelectual y moral" y formación en el lavado, planchado, cocina "y demás incumbencias de una sirvienta"1. Si bien el alojamiento en el Asilo y la formación ofrecida son gratuitos, es posible relativizar esa aparente gratuidad ya que el establecimiento se financia en parte con los trabajos que las mujeres realizan por turnos en su interior. La Asociación ofrece servicios por turnos en su interior, servicios de lavado y planchado de ropa y de elaboración de comidas, y convoca a las familias honradas a contribuir en la realización de los fines propuestos (Allemandi, 2005).

Las imágenes del Álbum de la Sociedad de Beneficencia, perteneciente al Archivo Privado y Museo del Asilo Unzué, ilustran lo descripto 
por Allemandi al hacer referencia a los valores económicos percibidos entre 1899 y 1909 por la institución, en relación a lo producido en los talleres por las labores femeninas en el marco de la Sociedad de Beneficencia. En este sentido en el discurso de Bernardino Rivadavia se evidencia las bases ideológicas imperantes que acompañan a estas instituciones en su accionar y formación de las pupilas, en relación a los valores éticos relacionados con su capacidad de producción:

“Viviendo las mujeres de su trabajo propio, y haciéndolo producir todo lo que es capaz, Ilevarían al unirse con el hombre, un capital exclusivamente suyo y un hábito de industria capaz de aumentarlo, que sería precisamente lo que, constituyéndolas independientes, las elevaría al rango de verdaderas compañeras, siéndoles tanto más honrosa esta independencia cuanto era conquistada por ellas mismas".

Este tipo de establecimientos brinda a los futuros patrones garantías, ya que las religiosas forman a las mujeres sobre determinados códigos éticos. Allemandi (2005) indica que una de las principales razones de la creación de esta institución, se centra en las dificultades que tienen los patrones para hallar sirvientas competentes y honradas, y por otro lado, el riesgo que implica para la introducción en el hogar de personas sin antecedentes. Es de destacar que la creación de estos establecimientos tiene su origen en Europa, remontándose hacia principios del siglo XIX en ciudades como Alemania, Bélgica y Francia. La mayoría están dirigidos por órdenes religiosas (tanto católicas como protestantes). A diferencia de estas, cobran por día por albergarlas y, quienes no podían afrontar esos gastos pagan con su trabajo el alojamiento, lo que por entonces es objeto de duras críticas. De todas formas, estos establecimientos estn pensados como lugares de tránsito (no de permanencia).

La asistencia de los niños pobres, huérfanos y abandonados, es un campo de acción compartido y de gran disputa por órdenes religiosas, funcionarios públicos y por la Sociedad de Beneficencia. Esta última es creada en 1823 por el gobierno de la Provincia de Buenos Aires, y su administración y dirección es encomendada automáticamente a mujeres pertenecientes a familias distinguidas y de clase alta del ámbito local. Haciendo referencia a lo descripto, en la Fig. 5 se muestra a personajes políticos y mujeres integrantes de la elite porteña en la ciudad de Mar del Plata, siendo estas últimas importantes figuras que pertenecen a las Damas de Beneficencia, las cuales tienen a su cargo el Asilo Saturnino Unzué entre otros establecimientos.

\section{FORMACIÓN Y LA COLOCACIÓN DE MENORES COMO SIRVIENTES: EL TRABAJO CONCEBIDO COMO HERRAMIENTA DE DISCIPLINAMIENTO}

La permanencia en los establecimientos es de tipo transitoria, ya que el destino habitual 


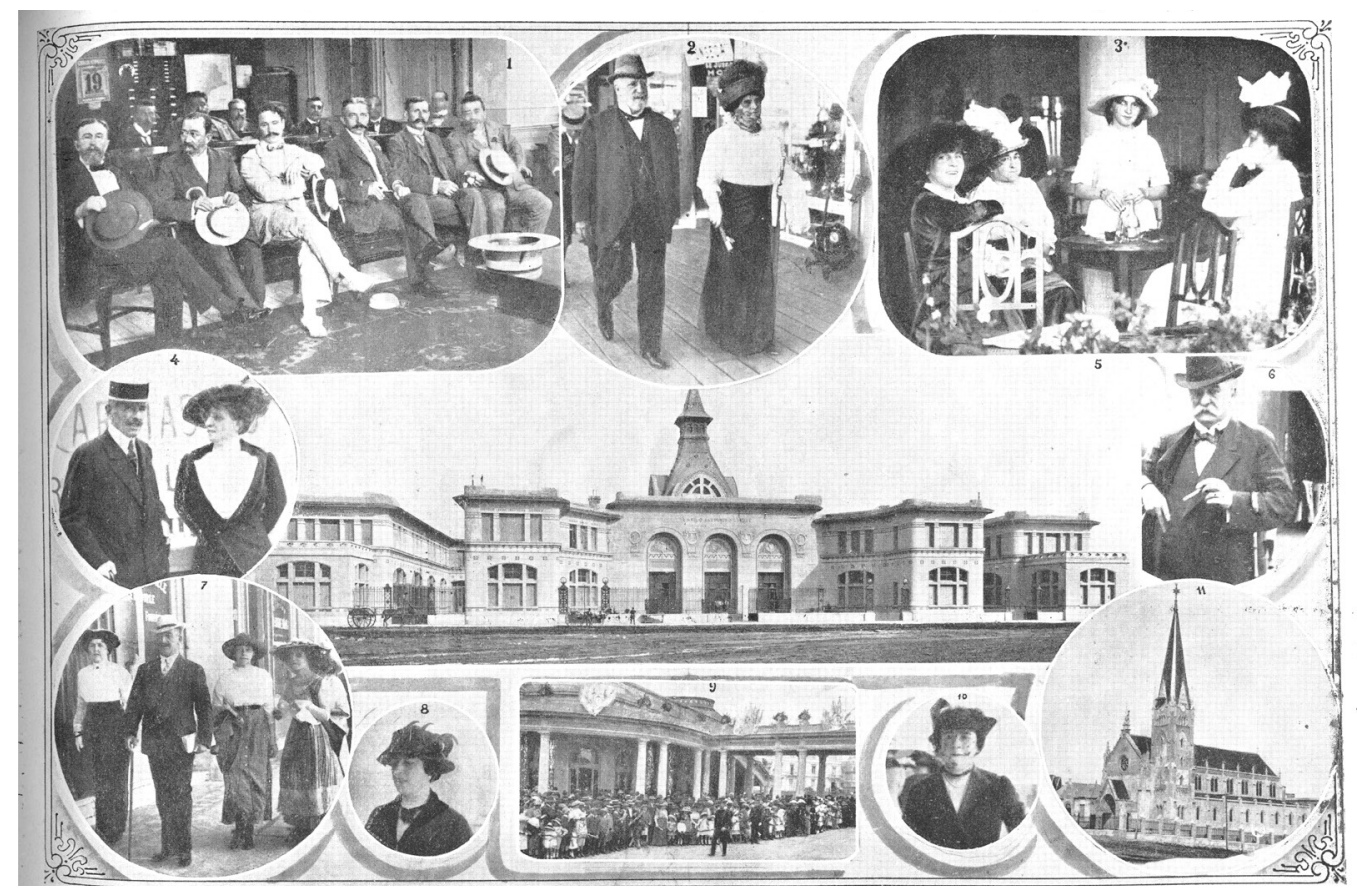

Figura 5.

El Asilo Unzué y las damas de la Beneficencia.

de la mayoría de ellos es la colocación. Como señala Aversa (2006), las autoridades públicas y asilares poseen herramientas administrativas y redes instituidas de entrega y circulación de menores mediante las cuales procuran protegerlos y "regenerarlos", encauzando de esta forma esas trayectorias de vida que causan preocupación por estar en la miseria y ser próximas al mundo del delito. Prevalece la idea de la "recuperación" de los menores por medio del trabajo, la cual está avalada por una diversidad de profesionales médicos, juristas, higienistas y abogados (intelectuales y de funcionarios públicos), e interactúa con las damas de la beneficencia y las órdenes religiosas.

El trabajo es concebido como una herramienta de disciplinamiento y moralización de las clases "menesterosas" pero así también como un mecanismo de contención e integración de menores, que deben ser objeto de tutela y protección oficial. Además, las colocaciones laborales permiten, por un lado, satisfacer las necesidades de alimentación y vestimenta de los niños, y de esta forma el Estado y la Sociedad de Beneficencia se desligan del sustento material al tiempo que descomprimen 
los asilos. Por otro lado, deben instruirlos en un oficio que les proporcione un medio para vivir y les permita integrase al orden social como trabajadores "útiles" y, así, corregir hábitos y costumbres nocivas adquiridas en el medio social de origen. (Figura 6.)

La instrucción en oficios y labores esta expresada en los postulados de la Misión del Asilo Unzué, enunciando:

"se asilan 350 niñas huérfanas donde reciben manutención, vestido y educación esmerada (...) Los cursos están incorporados a los programas oficiales de la provincia. Además (...), se les instruye especialmente en economía doméstica, manualidades y labores, donde se harán trabajos primorosos, que llaman la atención en las exposiciones que se realizan todos los años. Este asiloinstituto constituye (...) un modelo en su género, por la comodidad y amplitud de sus dependencias y por el régimen que en el mismo impera, a cargo de las Hermanas Franciscanas Misioneras de María (...) La institución se rige bajo los auspicios de la Sociedad de Damas de Beneficencia de la Capital, de la cual es presidenta la señora María Unzué de Alvear." (Figura 7)

Hacia fines del siglo XX, según Allemandi, algunos defensores de menores comienzan a cuestionar abiertamente a las damas de la beneficencia por promover la práctica habitual de retirar menores asilados para que se
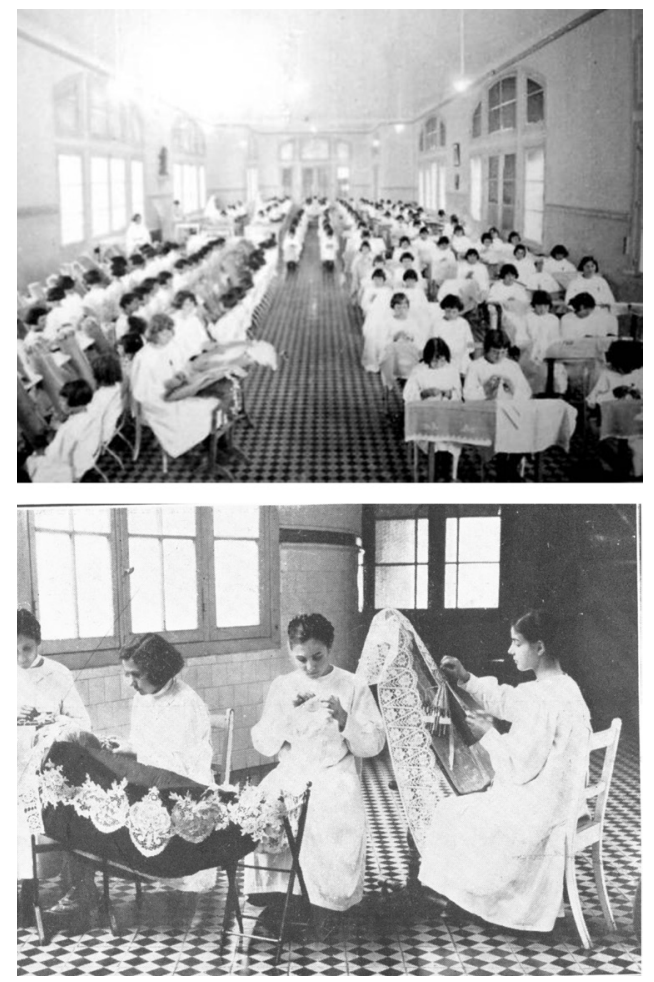

Figura 6.

(Arriba) Vista general de los Talleres - Asilo Unzué.

(Abajo) Asilo Saturnino Unzué - Taller de Labores

Fuente: Álbum de la Sociedad de Beneficencia.

Archivo Privado y Museo del Asilo Unzué. 


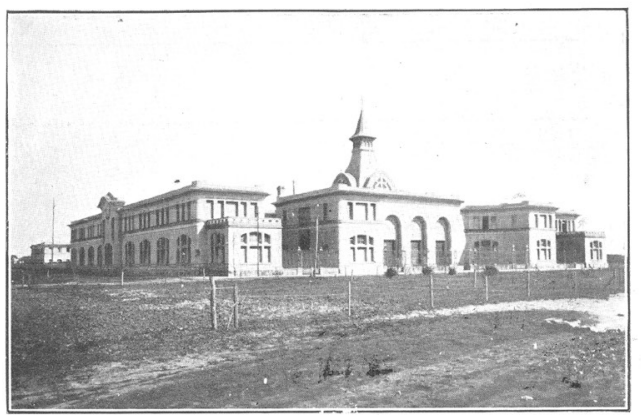

Frente principal sobre ef Boulevard Varítimo

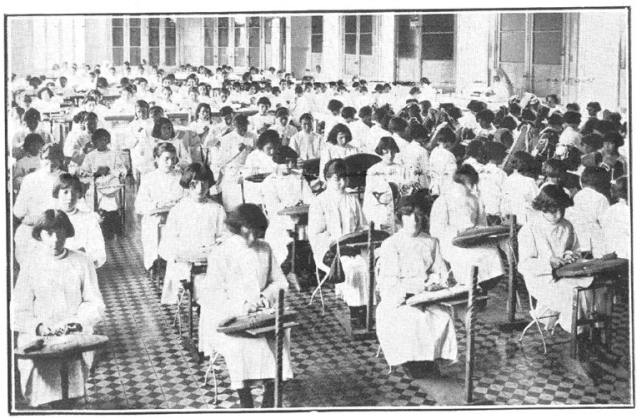

Isiladas en clace de labore

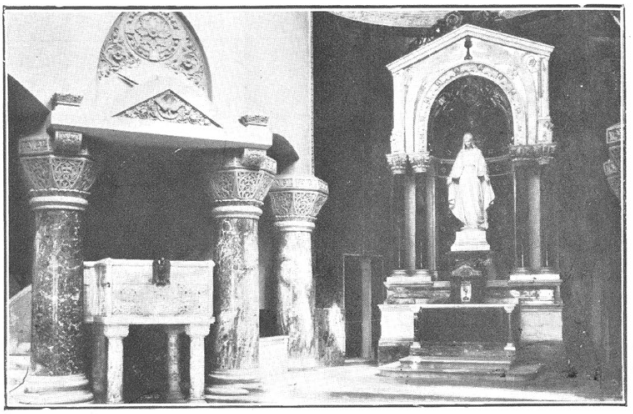

Capilla estilo Bizantino, Nltar y púlpito

\section{Asilo SATURNINO E. UNZUE BOULEVARD MARITIMO - U. Telef. 110}

Edificio donado por las señoras María Unzué de Alvear y Concepción Unzué de Casares, en memoria de sil señor padre don Saturnino Unzü. La institución fué fundada el 5 de Marzo de 1912 Misión de la misma

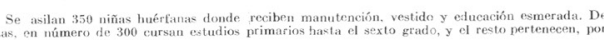
edad, al jardin de infantes.

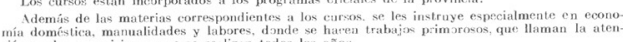
cín en las exposiciones que se realizan todos los años.
Este nsilo-instituto constituye, bien puede decirse, un modelo en su género. par la comodidad

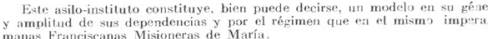
Tienen opecion de ingreso en este asilo hasta setenta niñas de Măr del Plate.

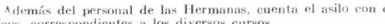
Tha institucín se rige bajo los auspicios de la Sociedad de Damas de Beneficencia de la Cay

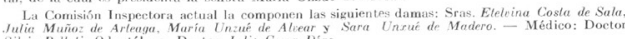

Figura 7.

Misión Asilo Unzué. Fuente: Álbum de la Sociedad de Beneficencia. Archivo Privado y Museo del Asilo Unzué.

desempeñen como sirvientes sin remuneración. En 1895 Adolfo Carranza, defensor de menores de la sección sud, eleva al Ministro de Justicia e Instrucción Pública una nota en donde señala que la Sociedad entrega menores sin control a quienes los solicitan con el pretexto de "adoptarlos como hijos" bajo condiciones objetables (2005). El defensor sostiene que de esta forma desde los 8 años los niños colocados pueden prestar servicios y, a partir de ello, el funcionario propone que los contratos se celebren en la Defensoría y que se aplique una escala salarial, planteando sin rodeos y blanqueando de esta forma que las relaciones creadas bajo el régimen de las colocaciones se centran en el trabajo. Estas propuestas, sin embargo, no tinen una respuesta favorable. A mediados de 1904, la Sociedad logra que el gobierno nacional apruebe un nuevo formulario para la colocación de menores, en el cual se establece que la Presidenta confía al "cuidado" de una Señora (en femenino) a una menor y se obliga a proceder como "madre cariñosa", otorgándole "educación moral y religiosa" y a satisfacer todos los gastos de sostenimiento de la persona que recibe. Si bien en este convenio 
ya no se explicita que la menor es entregada a su depositaria "para que le sirva", se puede afirmar que se trata de una relación laboral desde el momento que uno de sus artículos establece que, a partir de los 14 años de edad, la menor "ganaría un sueldo" que debe ser depositado en el Banco Nación en una libreta a su nombre y a la orden de la Sociedad.

En este sentido, Aversa (2006) señala que estos funcionarios ubican a los niños donde pueden $y$, bajo la consigna de formarlos en un oficio, $y$, de esta forma, terminan por facilitar el acceso de mano de obra infanto-juvenil a un muy bajo costo. Estas prácticas de colocación lejos de velar por una instrucción en oficios ligados a las demandas y necesidades de la economía, terminan por constituirse en un mecanismo de entrega de niños y niñas como sirvientes y criados sin demasiadas expectativas de progreso.

Remedi (2011) señala que con la crisis del paternalismo y la creciente mercantilización del servicio doméstico, en un contexto de transformaciones socio-políticas-económicas, no faltan quienes sentien cierta nostalgia por la antigua sirvienta o cocinera, cuya representación, quizás algo romántica, la presenta como aquella que pasa gran parte o toda su vida con la familia, considerada parte de ella, diligente, fiel, dócil, obediente, incluso afectuosa con sus patrones y sus hijos y de profundos sentimientos religiosos. En 1879, con ocasión de la instalación de una escuela de sirvientas, la prensa comenta que gracias a ella seguramente renace "esa raza de sirvientas antiguas, que eran un modelo de mujeres por su religiosidad y su laboriosidad".

\section{EL DISCIPLINAMIENTO DEL CUERPO Y LA INSTRUCCIÓN RELIGIOSA Y MORAL}

(...) una tecnología nueva: el desarrollo, del siglo XVI al XIX, de un verdadero conjunto de procedimientos para dividir en zonas, controlar, medir, encauzar a los individuos y hacerlos a la vez "dóciles y útiles". Vigilancia, ejercicios, maniobras, calificaciones, rangos y lugares, clasificaciones, exámenes, registros, una manera de someter los cuerpos, de dominar las multiplicidades humanas y de manipular sus fuerzas, se ha desarrollado en el curso de los siglos clásicos, en los hospitales, en el ejército, las escuelas, los colegios o los talleres: la disciplina.

Foucault, 1993

Dentro del disciplinamiento de las niñas y adolescentes, el control del cuerpo y el poder se ejerce sobre el cuerpo activo mediante técnicas que permiten un control minucioso de los movimientos y los gestos en el tiempo y espacio. En este sentido se trabaja sobre los cuerpos dóciles, como expresa Foucault en su libro Vigilar y castigar.

En la Fig. 8 se observa ese disciplinamiento corporal, donde el movimiento, las distancia entre las filas, está minuciosamente controlado 


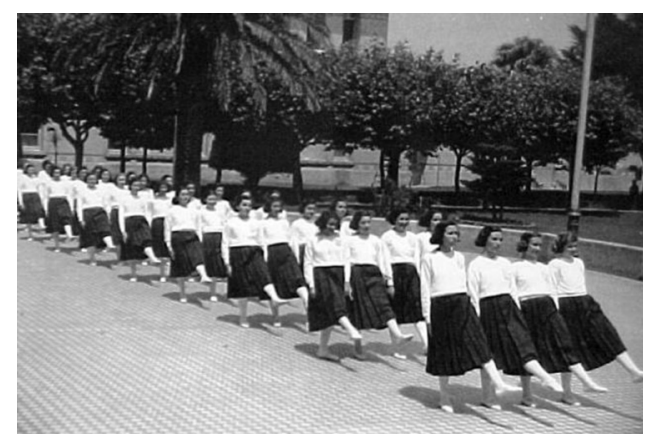

Figura 8.

Asilo Saturnino Unzué - Desfile en el Patio - "Cuerpos Dóciles". Archivo Privado y Museo del Asilo Unzué.

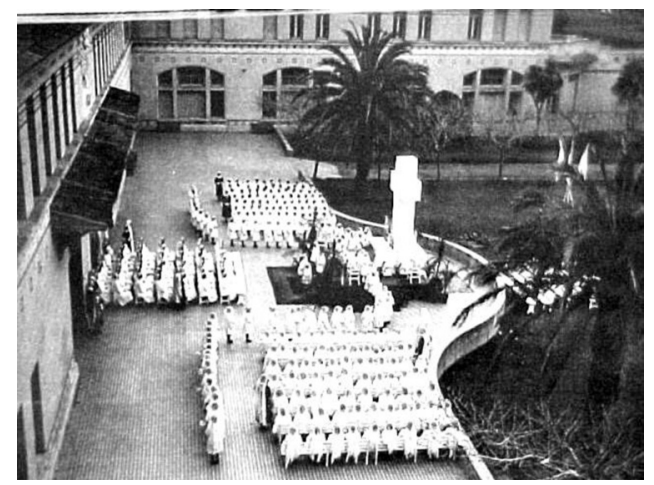

Figura 9.

Instrucción religiosa y moral. Archivo Privado y Museo del Asilo Unzué.. y pautado. Este disciplinamiento, es llevado a los uniformes, a la rigurosa estética de los cortes y peinados de las asiladas, donde se exhiben casi sin diferenciarse unas de otras. De esta forma se moldean los cuerpos para recibir las órdenes, casi como un cuartel de soldados, y así poder acatar los requerimientos de sus futuros patrones y presentarse dósiles ante la sociedad. (Figura. 8)

El objetivo es convertirlas en "personas honestas y útiles a la sociedad", para lo cual se les brinda instrucción religiosa y moral y se las prepara en una profesión u oficio adecuado a su clase y condición (Remedi, 2011). Una de las estrategias de este disciplinamiento y como modo de control es infundir el "temor de Dios", un temor constante, omnipresente, común a todos los internados e interiorizado en la conciencia de cada uno de ellos en diversas instituciones asilares. (Fig. 9)

\section{PALABRAS FINALES}

Desde una perspectiva foucaltiana, a través del análisis de los casos de estudio, referidos a obras pertenecientes a la Sociedad de Beneficencia de la Capital en la ciudad de Mar del Plata, se pueden explorar diversas aristas desde un enfoque más profundo sobre el sentido de la instalación de estos "dispositivos disciplinares" en la ciudad de Mar del Plata.

Reconocer como a través de las formas espaciales, instituciones y reglamentaciones, 
se pueden vislumbrar estos mecanismos disciplinares que se encuentran en la matriz de gestación de las mismas.

Poder explorar a través de esta perspectiva aquellas instituciones edificios y prácticas sociales que se instauraron como instrumentos disciplinares, permite repensar nuestra sociedad que aún hoy refleja estos dispositivos, moldeando "individuos útiles" para responder a los sistemas económicos y políticos imperantes, "sociedad disciplinaría de la que seguimos dependiendo" como define Foucault.

\section{BIBLIOGRAFÍA}

ALLEMANDI, C. (2005). Sirvientes, criados y nodrizas. Una aproximación a las condiciones de vida y de trabajo en la ciudad de Buenos Aires a partir del servicio doméstico (fines del siglo XIX-principios del XX). Tesis.

AMUCHÁSTEGUI, R. (2008). Michel Foucault y la Visoespacialidad. Análisis y Derivaciones. Disponible en: http://www.eumed.net/tesisdoctorales/2009/rha

AVERSA, M. (2006). “Infancia abandonada y delincuente. De la tutela provisoria al patronato público (1910-1931)". En Lvovich, D. \& Suriano, J. (editores). Las políticas sociales en perspectiva histórica, Argentina, 1870-1952. Buenos Aires: Prometeo Libros.

CASTRO, E. (2004). El vocabulario de Michel Foucault. Buenos Aires: Prometeo/3010, UNQ.

CAMERON, D. \& MARKUS, T. (2002). The words between the spaces: buildings and language. London New York: Routledge.

FIORENTINO, R.(2013). "Una Obra de Baldassarini para la Sociedad de Beneficencia”. En Orígenes del Patrimonio Asistencial en el Balneario Nacional. Mar del Plata: Universidad Nacional de Mar del Plata, p. 92- 97.

FISCHLER, R. (1995). "Estrategia e historia en la práctica profesional. La planificación como creación de mundo". En Prácticas del espacio. Exploraciones críticas en la teoría social y espacial. 
FOUCAULT, Michel (1988 [1971]) Nietzsche, La Genealogía, La Historia. Traducción José Vázquez Pérez España: Plaza de edición.

FOUCAULT, M. (1978). Microfísica del poder. Madrid: Las Ediciones de La Piqueta.

FOUCAULT, M. (1979). El ojo del poder. En BENTHAM, J., 1979, “El Panóptico". Entrevista con Michel Foucault. Traducción de Julia Varela y Fernando Álvarez-Uría. Barcelona: Ediciones la Piqueta, 1980. Disponible en: http://rie. $\mathrm{cl} / \mathrm{?}=1009$.

FOUCAULT, M. (1993). Vigilar y castigar: El nacimiento de la prisión. México: Siglo XXI (1a edición en francés: 1984).

FOUCAULT, M. (2005). El poder psiquiátrico. México: FCE.

LOBATO, M. (2007). “Capítulo 2 “El hogar y la fábrica: las condiciones de trabajo”. En Historia de las trabajadoras en la Argentina (18691960). Buenos Aires: Edhasa.

MARTÍNEZ-NOVILLO, J. (2010). “Genealogía y Discurso. De Nietzsche a Foucault”. En Nómadas, Revista Crítica de Ciencias Sociales y Jurídicas, 26 , (2010.2). Disponible en https:// pendientedemigracion.ucm.es/info/nomadas/26/javierrujas.pdf

MORENO, J. (comp.) (2000). La política social antes de la política social. Caridad, beneficencia y política social en Buenos Aires, siglos XVIII a XX. Buenos Aires: Prometeo.

PARÍS BENITO, F. (et al). (2013). Orígenes del patrimonio asistencial en el balneario nacional. Mar del Plata: Universidad Nacional de Mar del Plata.
RAFFA, C. (2007) El modelo panóptico en la arquitectura penitenciaria argentina: la primera cárcel en la ciudad. Mendoza, 1864. En Argos v.24 n.47, Caracas jul. 2007. Disponible en: http://www.scielo.org.ve/scielo.php?pi$d=$ S0254-16372007000200003\&script=sci_arttext

REMEDI, F. (2011). Esta descompostura general de la servidumbre. Las trabajadoras del servicio doméstico en la modernización argentina. Córdoba, 1869-1906. Secuencia (84) México sep./dic. 2012.

SCOTT, J. (1990). El género: una categoría útil para el análisis histórico. En James, A. \& $\mathrm{NASH}, \mathrm{M}$. (eds.), Historia y género: las mujeres en la Europa moderna y contemporánea. Edicions Alfons el Magnanim, Institució Valencina d Estudis i Investigació.

\section{OTRAS FUENTES CONSULTADAS}

- AA.V. Álbum de la Sociedad de Beneficencia de la Capital 1823-1910.

-_-_ AA.VV. Origen y desenvolvimiento de la Sociedad de Beneficencia en la Capital, 18231912. Buenos Aires aprox. 1913.

-- ARCHIVO GENERAL DE LA NACIÓN. Documentos escritos. Instituciones de la sociedad de Beneficencia de la Capital 1823-1952. Buenos Aires 1999.

REGLAMENTO DEL ASILO DE HUÉRFANOS, en Compilación, 1870, t. 2, pp. 410-413.

ESTATUTOS SOCIEDAD DAMAS DE LA VIRGEN DEL MILAGRO, en Compilación, 18781906, pp. 369-379. 
SOCIEDAD DE BENEFICENCIA DE LA CAPI-

TAL, Su origen y su desenvolvimiento 18231904., Buenos Aires 1905.

SOCIEDAD DE BENEFICENCIA DE LA CAPITAL, Su origen y su desenvolvimiento 1823 1923. Buenos Aires 1924.

BUSCHIAZZO, M. La arquitectura en la República Argentina 1810-1930. Buenos Aires, Mac Gaul, 1971.

CONI, E. Asistencia y previsión social, Buenos Aires, Emilio Spinelli, 1918.

CORREA LUNA, C. Historia de la Sociedad de Beneficencia, Buenos Aires, Sociedad de Beneficencia de la Capital, 1923. t.l: 1823-1852.

DE DIOS DE MARTINA, Á. (2010). Los congresos femeninos del Centenario. Análisis de sus antecedentes, sesiones y trabajos, Resistencia, Junta de Estudios Históricos del Chaco, (inédito).

MEYER ARANA, A. (1911). La caridad en Buenos Aires, Buenos Aires, Comisión Nacional del Centenario, t.Il.

COTTINI, A. (1977). El hospital, Programación arquitectónica. Universidad de Mendoza, Facultad de Arquitectura y Urbanismo.

FACCIUITO, A. (2005). La Sociedad de Beneficencia. Lo oculto en la Bondad de una época, Edición Espacio. ISBN 950-802-193-4, Buenos Aires.

JORGE, J. \& DIETSCH, J. (1934). Clima de Mar y Sanatorios Marítimos, Sociedad de Beneficencia de la Capital, Buenos Aires.
JORGE, J. (1932). “Sanatorio Marítimo y Solárium de Mar del Plata, en Revista Médica 1932. Buenos Aires.

KOHL, A. (2006). Higienismo argentino. Historia de una utopía. Editorial Dunkenl. ISBN 987 02-1943-8, Buenos Aires.

MADRID PAEZ, S. (1923). Sociedad de Beneficencia de la Capital. Su misión y sus obras 1823-1923. Buenos Aires.

SANCHEZ, N. (2007). La higiene y los higienistas en la argentina 1880-1943. Sociedad científica argentina. Buenos Aires 